\title{
Images in Cardiology -Skin Lesions in Native Valve Infective Endocarditis
}

\author{
Rushikesh $\mathrm{SP}^{1}$ and Ganeshkumar $\mathrm{AV}^{2 *}$ \\ ${ }^{1}$ Consultant Cardiologist, Dr. LH Hiranandani Hospital, India
}

${ }^{2}$ Department of Cardiology, Dr. LH Hiranandani Hospital, India

Submission: February 27, 2018; Published: April 13, 2018

*Corresponding author: Ganeshkumar AV, Head, Department of Cardiology, Dr. LH Hiranandani Hospital, Mumbai, India, Email: ganeshavk@hotmail.com

\section{Introduction}

Janeway's lesions are non tender small erythematous or hemorrhagic macular or nodular lesions on the palms or soles; they rarely present as a diffuse rash, and are rare in clinical practice [1]. Possibly the lesions are the result of septic micro emboli that originate from the endocardium, a fact that has been substantiated by histopathological studies in the literature [2]. Pathologically, the lesion is described to be a micro abscess of the dermis with marked necrosis and inflammatory infiltrate [3]. However Osler's nodes are painful, erythematous nodules on the pads of the fingers and toes are more commonly seen in patients with subacute bacterial endocarditis. It is believed that the nodes are caused by an immunologically-mediated vasculitis caused by circulating immune complex deposition in the skin [4].

A 20 year old man presented with high grade fever with chills $\&$ rigors associated with body ache, headache of 15 days duration without any significant past medical history. Patient was febrile on presentation (axillary temperature $39.3^{\circ} \mathrm{C}$ ), normotensive but sinus tachycardia at a rate of 110 beats/minute and icterus. His skin evaluation showed painful erythematous nodule on finger pulp \& toe (Figure 1); erythematous macular painless rashes distributed along the palms and sole (Figure 2), with subungual splinter hemorrhages (Figure 3). His systemic examination revealed mild spleenomegaly \& harsh pansystolic murmur at apex. Lab investigations revealed leukocytosis with thrombocytopenia and deranged renal \& hepatic parameters ( $\mathrm{Hb}-10.6 \mathrm{gm} \%$, TLC $13000 /$ cumm, Platelet count of 20000/cumm, Serum. Bilirubin Total $2.4 \mathrm{mg} \%$ (direct $1.4 \mathrm{mg} \%$ and Indirect $1.0 \mathrm{mg} \%$ ), SGOT 100IU/L, SGPT 46IU/L, Serum Creatinine 3.4mg\%, BUN 78.5mg\%, serum $\mathrm{Na}+135 \mathrm{meq} / \mathrm{l}, \mathrm{K}+3.3 \mathrm{meq} / \mathrm{L}$ ). Urine examination revealed microscopic haematuria with RBCs.

The diagnosis of infective endocarditis was confirmed by evidence of endocardial involvement with echocardiographic demonstration of vegetation attached to the mitral valve (Figure 4), with Janeway's lesion, Osler's node \& glomerulonephritis. Blood culture failed to grow any pathogenic organism (likely due to initiation of antibiotics at another center on outpatient basis). The patient was treated with intravenous antibiotics (ceftriaxone and gentamicin) with good clinical respon
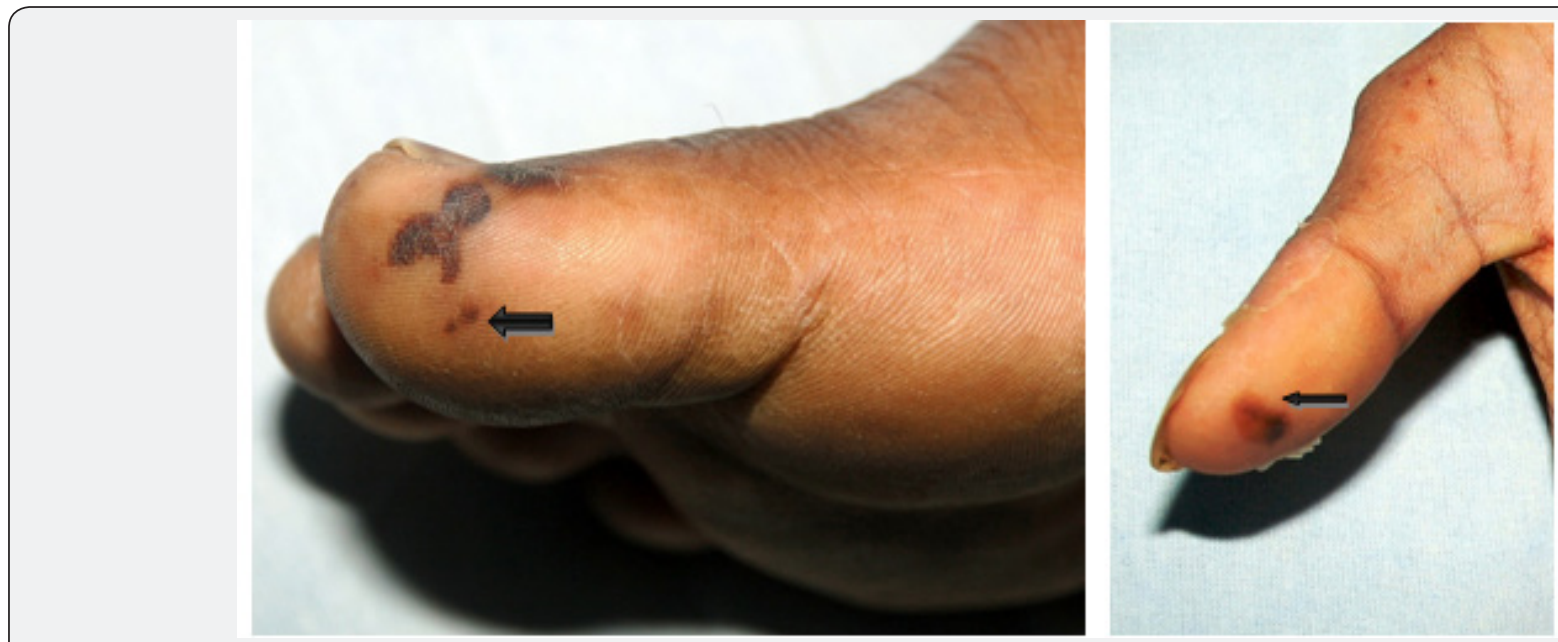

Figure 1: Osler's nodes (arrow mark). 

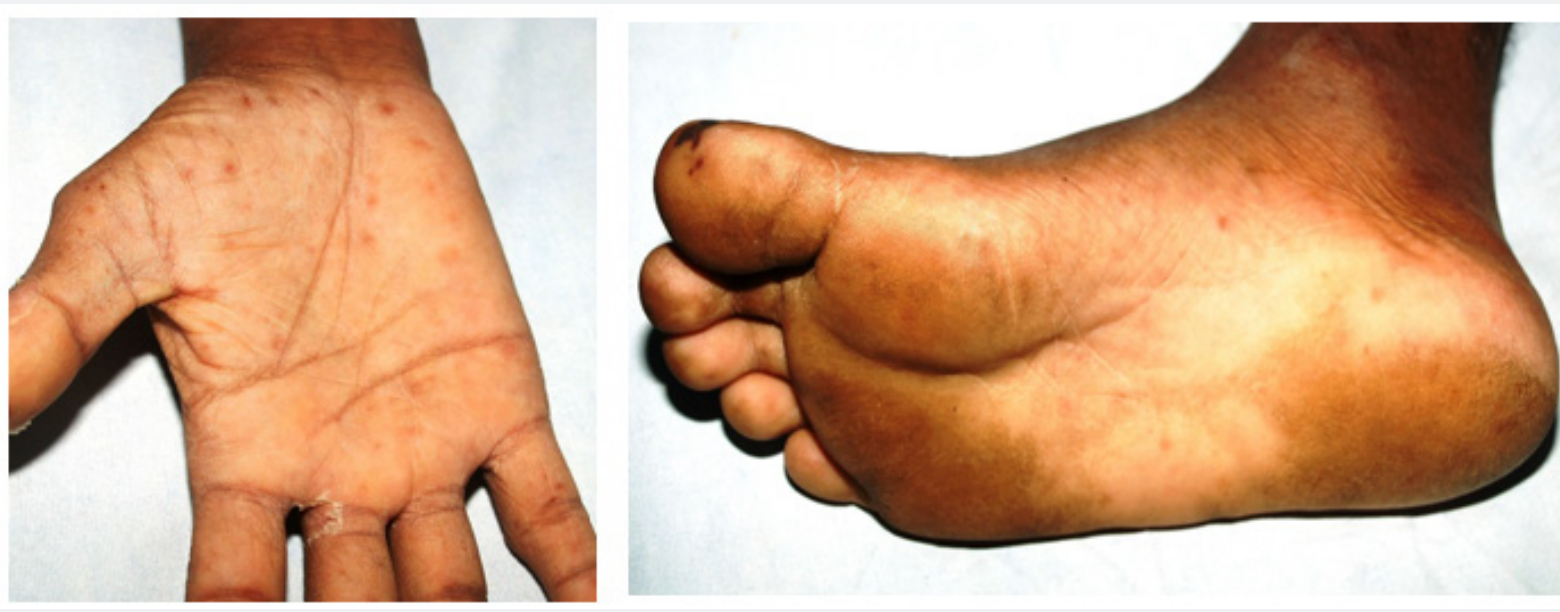

Figure 2: Janeway's lesions.

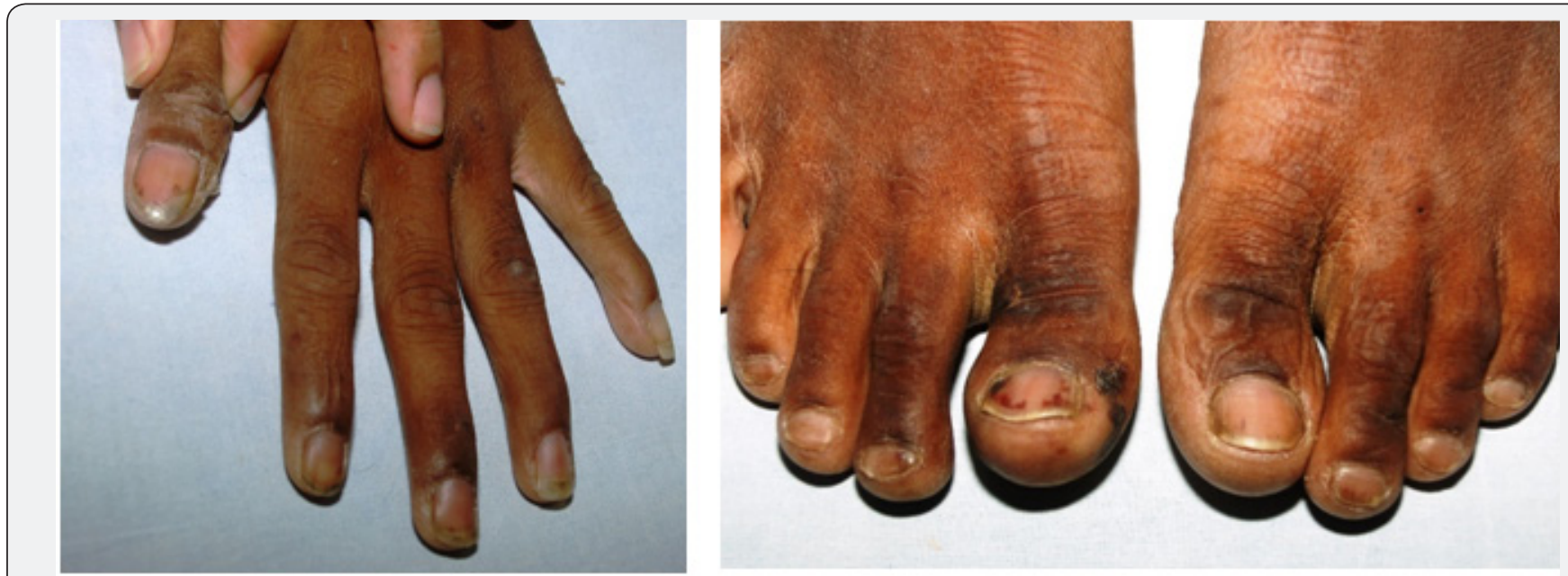

Figure 3: Splinter hemorrhages.
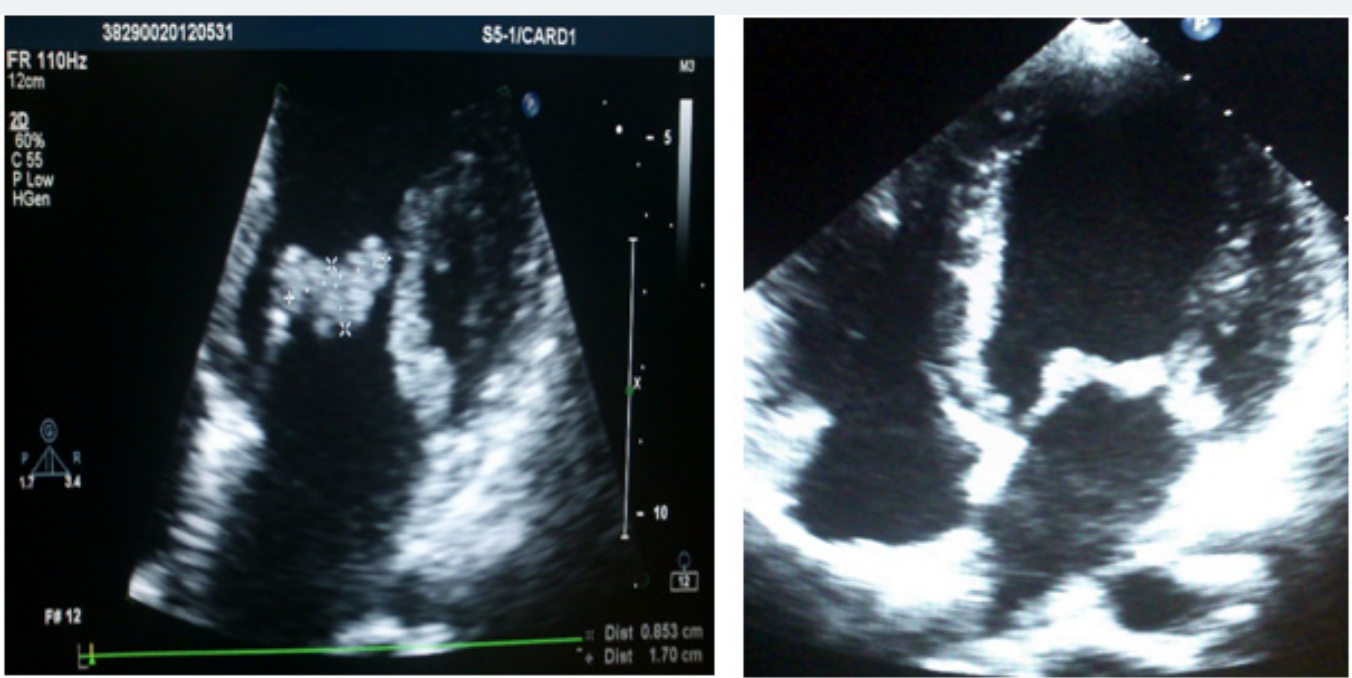

Figure 4: Echocardiography showing vegetation on AML. 


\section{References}

1. Farrior JB, Silverman ME (1976) A consideration of the differences between a Janeway's lesion and an Osler's node in infectious endocarditis. Chest 70(2): 239-243.

2. Vinson RP, Chung A, Elston DM, Keller RA (1996) Septic microemboli in a Janeway lesion of bacterial endocarditis. J Am Acad Dermatol 35(6): 984-985.
3. Mandell G, Bennett J, Dolin R (2009) Mandell, Douglas, and Bennett's principles and practice of infectious diseases. ( $7^{\text {th }}$ edn), Churchill Livingstone, UK.

4. Yee J, McAllister CK (1987) Osler's nodes and the recognition of infective endocarditis: a lesion of diagnostic importance. South Med J 80(6): 753-757.

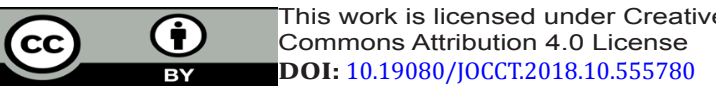

